\title{
COMMENTARY
}

\section{Is acute respiratory distress syndrome an iatrogenic disease?}

\author{
Jesús Villar ${ }^{1,2,3}$ and Arthur S Slutsky*3,4,5 \\ See related research by Determann et al., http://ccforum.com/content/14/1/R1
}

\begin{abstract}
In this month's issue of Critical Care, Determann and colleagues report the results of a randomized controlled trial comparing the effects of mechanical ventilation (MV) with two tidal volumes (6 versus $10 \mathrm{ml} / \mathrm{kg}$ predicted body weight) on cytokine levels in lung lavage fluid and plasma as a surrogate for early identification of acute lung injury (ALI) and/ or acute respiratory distress syndrome (ARDS). The study was stopped early after an interim analysis when 150 patients were enrolled - showing that the incidence of ALI/ARDS according to the current definition was $10.9 \%$ higher in the $10 \mathrm{ml} / \mathrm{kg}$ group, although duration of MV and mortality was similar in both groups. We examine these interesting results after providing a brief historical perspective and discuss the limitations and implications of the study.
\end{abstract}

Mechanical ventilation (MV) is the second most frequent therapeutic intervention performed in ICUs (after treatment of cardiac arrhythmias), and is the most important intervention in patients with respiratory failure. However, it is associated with several complications, including increased risk of pneumonia, impaired cardiac function, and development of lung injury. There is now unequivocal evidence from both experimental and clinical studies that MV can cause or aggravate acute lung injury (ALI) - a concept termed ventilator-induced lung injury (VILI). Many of the pathophysiological consequences of VILI mimic those of acute respiratory distress syndrome (ARDS) [1]. Is this relationship a coincidence or could there be a more sinister explanation - we address this issue later in this commentary.

*Correspondence: slutskya@smh.toronto.on.ca

${ }^{3}$ St Michael's Hospital, 30 Bond Street, Toronto, Ontario M5B 1W8, Canada Full list of author information is available at the end of the article
In the 1960s, pathologists recognized a new, severe pulmonary lesion that they called 'respirator lung'; in the 1970s Webb and Tierney developed a model of VILI [2], and in the late 1980s Dreyfuss and colleagues determined that lung stretch was a critical factor leading to VILI [1]. In 1998 Tremblay and Slutsky [3] coined the term 'biotrauma' to describe the pulmonary and systemic inflammatory response triggered by lung cell distension, disruption, and/or necrosis after the application of MV. Although a Consensus Conference in 1994 recommended that plateau pressure should generally be limited to 35 $\mathrm{cmH}_{2} \mathrm{O}$ [4], little change in ventilator practice occurred until publication of the ARDS Network study [5], which demonstrated that a lung protective strategy using a tidal volume $\left(\mathrm{V}_{\mathrm{T}}\right)$ of $6 \mathrm{ml} / \mathrm{kg}$ predicted body weight decreased mortality in patients with ALI. This study confirmed that VILI was not just an interesting experimental entity, but was also an important clinical problem. This study led to the widespread, albeit not universal, use of lung protective strategies in patients with ALI.

However, the ARDS Network trial did not address the issue of how to ventilate patients who do not have ALI [6]. On the one hand, one could argue that such a strict lung protective strategy using small tidal volumes is not necessary as these patients do not have widespread pulmonary changes observed in patients with ALI and are therefore not at great risk of VILI. Furthermore, the use of low $V_{T}$ might lead to de-recruitment of lung units, increased hypoxemia and hypercapnia. On the other hand, the upper limit of plateau pressure that ensures lung protection may be substantially lower than $30 \mathrm{cmH}_{2} \mathrm{O}$, and small $\mathrm{V}_{\mathrm{T}}$ may be beneficial [7]. Evidence that lower $\mathrm{V}_{\mathrm{T}}$ may be advantageous in patients without ALI has been provided by observational studies demonstrating that ventilation with higher $\mathrm{V}_{\mathrm{T}} \mathrm{S}$ early in the ICU course is associated with subsequent development of ALI [8,9]. However, observational studies are prone to bias, particularly because it is not clear why the attending physician chose a large versus small $\mathrm{V}_{\mathrm{T}}$ for any given patient. As such, a randomized trial addressing the hypothesis that a small $V_{T}$ could prevent or attenuate 
VILI in critically ill patients without ALI/ARDS is important and timely.

In this issue of Critical Care, Determann and colleagues [10] report the results of a randomized controlled trial comparing two $\mathrm{V}_{\mathrm{T}} \mathrm{s}$ (6 versus $10 \mathrm{ml} / \mathrm{kg}$ predicted body weight) in ventilated patients without ALI. Bronchoalveolar lavage fluid and plasma cytokine levels were used as surrogate endpoints for early identification of the pulmonary inflammation associated with ALI. The study was stopped prematurely after the second interim analysis ( $\mathrm{n}=150$ patients) because investigators from one of the two participating centres were uncomfortable continuing the study since the development of ALI was significantly greater in the control arm. Methodologically, this is somewhat unusual in that current practice is that interim analyses are carried out by a committee who are not investigators in the study [11]; indeed, it is uncommon for investigators to even be aware of interim outcome data by study group. We think that stopping the trial early was unnecessary and unfortunate; there was no strong safety signal, with virtually identical trends in terms of duration of MV and mortality rate in both groups. Early stopping tends to overestimate treatment effects $[12,13]$; this is particularly true for studies with low event rates, as was the case in this study, in which only 12 patients in total developed ALI.

What conclusions can be drawn from the paper by Determann and colleagues? First, there are insufficient data to conclude that all ICU patients must be ventilated with a $\mathrm{V}_{\mathrm{T}}$ of $6 \mathrm{ml} / \mathrm{kg}$. We agree with the authors who recommend that a large randomized controlled trial is needed before being able to draw this conclusion. Nonetheless, using small $\mathrm{V}_{\mathrm{T}} \mathrm{S}$ in patients without ALI may be a reasonable strategy, and there appears to be little evidence of harm if clinicians address issues related to maintenance of sufficient positive end-expiratory pressure (PEEP), and possibly the respiratory acidosis that may arise.

Second, as hinted at above, it is interesting to speculate on the relationship between MV and ALI. If Determann and colleagues' data are correct, should we begin to consider that ALI/ARDS is a consequence of our efforts to ventilate patients, rather than progression of the underlying disease [14]? Injurious ventilatory strategies have been shown to increase alveolar-capillary leak, worsen oxygenation, cause pulmonary infiltrates, decrease lung compliance and cause an increase in lavage and systemic cytokines - all hallmarks of ALI/ARDS. In the context of increased alveolar-capillary leak, use of excessive intravenous fluids - often used to treat shock in patients at risk for ALI - can cause increased lung water, and again worsen mechanics and gas exchange, and indeed worsen clinical outcomes. It may not be a coincidence that ARDS was first described in the late 1960s, at the time of the Vietnam war - it is also called 'Da Nang lung' or 'shock lung' - when patients were resuscitated aggressively on the battle-field. Finally, endotracheal intubation affects host defence and can lead to development of colonization/pneumonia, a predisposing factor for ALI. As such, is ALI/ARDS largely a 'man-made' syndrome, and is it a consequence of the aggressive regimens we have adopted to treat acutely ill patients? If so, and if the results of Determann and colleagues vis-à-vis the marked decrease in development of ALI in patients treated with low $\mathrm{V}_{\mathrm{T}}$ turns out to be correct, it would mark an inflection point in which ALI/ ARDS is no longer a syndrome that must be treated, but is a syndrome that should be prevented.

\section{Abbreviations}

$\mathrm{ALI}=$ acute lung injury; $\mathrm{ARDS}=$ acute respiratory distress syndrome; $\mathrm{MV}=$ mechanical ventilation; $\mathrm{VILI}=$ ventilator-induced lung injury; $\mathrm{V}_{\mathrm{T}}=$ tidal volume.

\section{Acknowledgements}

$J V$ is supported by grants from Fondo de Investigación Sanitaria of Spain (\#07/0113), and AS from the Canadian Institutes of Health Research.

\section{Authors' contributions}

$\mathrm{JV}$ and AS equally participated in the writing of the drafts and the final manuscript.

\section{Author details}

'CIBER de Enfermedades Respiratorias, Instituto de Salud Carlos III, Madrid, Spain

${ }^{2}$ Multidisciplinary Organ Dysfunction Evaluation Research Network, Research Unit, Hospital Universitario Dr. Negrin, Las Palmas de Gran Canaria, Spain ${ }^{3}$ Keenan Research Center at the Li Ka Shing Knowledge Institute of St. Michael's Hospital, Toronto, Ontario M5B 1W8,Canada

${ }^{4}$ Interdepartmental Division of Critical Care Medicine, University of Toronto, Toronto, Canada

${ }^{5}$ Adjunct Professor, King Saud University, Riyadh, Saudi Arabia

\section{Competing interests}

The authors declare that they have no competing or financial interests related to the content of the manuscript.

Published: 16 February 2010

\section{References}

1. Dreyfuss D, Soler P, Basset G, Saumon G: High inflation pressure pulmonary edema: respective effects of high airway pressure, high tidal volume, and positive end-expiratory pressure. Am Rev Respir Crit Dis 1988, 137:1159-1164.

2. Webb HH, Tierney DF: Experimental pulmonary edema due to intermittent positive pressure ventilation with high inflation pressures. Protection by positive end-expiratory pressure. Am Rev Respir Dis 1974, 110:556-565.

3. Tremblay LN, Slutsky AS: Ventilator-induced injury: from barotraumas to biotrauma. Proc Assoc Am Physicians 1998, 110:482-488.

4. Slutsky ASL: Consensus Conference on mechanical ventilation. Intensive Care Med 1994, 20:64-79.

5. Acute Respiratory Distress Syndrome Network: Ventilation with lower tidal volumes as compared with traditional tidal volumes for acute lung injury and the acute respiratory distress syndrome. N Engl J Med 2000, 342:1301-1308.

6. Schultz MJ, Haitsma JJ, Slutsky AS, Gajic O: What tidal volumes should be used in patients without acute lung injury? Anesthesiology 2007 106:1226-1231.

7. Hager DN, Krishnan JA, Hayden DL, Brower RG; ARDS Clinical Trials Network: Tidal volume reduction in patients with acute lung injury when plateau pressures are not high. Am J Respir Crit Care Med 2005, 172:1241-1245.

8. Gajic O, Dara SI, Mendez JL, Adesanya AO, Festic E, Caples SM, Rana R, St Sauver JL, Lymp JF, Afessa B, Hubmayr RD: Ventilator-associated lung injury 
in patients without acute lung injury at the onset of mechanical ventilation. Crit Care Med 2004, 32:1817-1824.

9. Yilmaz M, Keegan MT, Iscimen R, Afessa B, Buck CF, Hubmayr RD, Gajic O: Toward the prevention of acute lung injury: protocol-guided limitation of large tidal volume ventilation and inappropriate transfusion. Crit Care Med 2007, 35:1660-1666.

10. Determann RM, Royakkers A, Wolthius EK, Vlaar AP, Choi G, Paulus F, Hofstra JJ, de Graaff MJ, Korevaar JC, Schultz MJ: Ventilation with lower tidal volumes as compared to conventional tidal volumes for patients without acute lung injury: a preventive randomized controlled trial. Crit Care 2010, 14:R1.

11. Slutsky AS, Lavery JV: Data safety and monitoring boards. N Engl J Med 2004, 350:1143-1147.

12. Montori VM, Devereaux PJ, Adhikari NK, Burns KE, Eggert CH, Briel M, Lacchetti C, Leung TW, Darling E, Bryant DM, Bucher HC, Schünemann HJ, Meade MO, Cook DJ, Erwin PJ, Sood A, Sood R, Lo B, Thompson CA, Zhou Q,
Mills E, Guyatt GH: Randomized trials stopped early for benefit: a systematic review. JAMA 2005, 294:2203-2209.

13. Bassler D, Montori VM, Briel M, Glasziou P, Guyatt G: Early stopping of randomized clinical trials for overt efficacy is problematic. J Clin Epidemiol 2008, 61:241-246.

14. Villar J, Kacmarek RM, Hedenstierna G: From ventilator-induced lung injury to physician-induced lung injury: Why the reluctance to use small tidal volumes? Acta Anaesthesiol Scand 2004, 48:267-271.

doi: $10.1186 /$ cc8842

Cite this article as: Villar J, Slutsky AS: Is acute respiratory distress syndrome an iatrogenic disease? Critical Care 2010, 14:120. 